\title{
INFLUENCE OF THE CYCLIC HARDENING MODEL ON THE RESULTS OF THE NUMERICAL ANALYSIS OF FATIGUE LIFE ON EXAMPLE OF THE COMPRESSOR BLADE
}

\author{
Arkadiusz Bednarz \\ Rzeszow University of Technology, Department of Aircraft and Aircraft Engines \\ Powstancow Warszawy 12, 35-959 Rzeszow, Poland \\ tel. +48177432348 \\ e-mail:abednarz@prz.edu.pl \\ Lehigh University, Department of Mechanical Engineering and Mechanics \\ 27 Memorial Dr W, Bethlehem, PA 18015, United States
}

\begin{abstract}
The main goal of the presented work is to determine the impact of the cyclic hardening model on the numerical results of the $\varepsilon-N$ fatigue test. As an object of study, compressor blade (from PZL-10W helicopter engine) was used. The examined blade was made of EI-961 alloy. In numerical analysis, a geometrical model of the blade with a preliminary defect was created. Geometrical defect - V-notch was created on the leading edge. This defect was introduced in order to weaken the structure of the element and the possibility of observing the crack initiation process (in experimental tests). Material data to $\varepsilon-N$ analysis, based on Manson-Coffin-Basquin equation, were estimated for Mitchell's model. This model was built based on strength data provided by the steel producer. Based on three different models of cyclic hardening (Manson, Fatemi, and Xianxin), a number of load cycles were calculated. Load cycle during numerical analysis was represented as resonance bending with an amplitude of displacement equal to $A=1.8 \mathrm{~mm}$. Obtained results were compared with experimental data. Additionally, the analytical model of $\varepsilon-N$ fatigue (depending on the cyclic hardening) was prepared. All the work carried out has been summarized by a comprehensive comparative analysis of the results. Obtained results and dependencies can be used in the selection of an appropriate model of cyclic hardening in further fatigue tests of many aerospace elements.
\end{abstract}

Keywords: fatigue life, compressor blade, aircraft engine, cyclic hardening, numerical analysis

\section{Introduction}

The blades of aircraft engine compressors are one of its most important components, ensuring operational safety and aircraft performance $[1,3]$. The compressor blades run at speeds exceeding 40,000 RPM, generating a pressure increase several dozen times. The high speed, in combination with the centrifugal force and the incoming pressure, can deflect the blade. In addition, the compressor blade is exposed to vibrations resulting from the pulsation of the working medium and possible unbalance of the rotor. When discussing the operating conditions of the aircraft engine's compressor blades, it should also be taken into account that the first stage of the compressor is in particular exposed to collision damage with a hard element sucked into the engine [4]. The occurrence of the resonance situation (caused by vibrations) [6], combined with foreign object damage may be the cause of the crack initiation [1], which may result in engine damage or even failure of the aircraft $[3,16]$.

The development of numerical methods and computing power allowed increasing the significance of the finite element method in fatigue analysis. Modern computational methods are based on the mathematical equations of the mechanical phenomenon's [10]. One of the most important issues related to fatigue durability is the phenomenon of cyclic metal hardening. Fatigue analysis $\varepsilon-\mathrm{N}$ is based on the Manson-Coffin-Basquin model. This model (in contrast to the Wohler curve used in the S-N analysis) is determined using fatigue material data. Unfortunately, the $\varepsilon-\mathrm{N}$ 
fatigue analysis, on the one hand, requires a linear-elastic model of a material (static analysis based on Young's E modulus), and on the other requires the knowledge of total (elastic and plastic) deformations. In order to convert elastic strains (from linear analysis) into total strains, in the case of metals, the cyclic hardening model described by Ramberg and Osgood is used. Both the MansonCoffin-Basquin fatigue model and the Ramberg-Osgood hardening model require estimation of a number of material values, based on data from a static tensile test. There are several methods for estimating data for fatigue analysis $\varepsilon-\mathrm{N}$. In this work, the Mitchell model was used, characterized by the simplicity of determining constants. In the case of the hardening model, three models were selected for this work: Manson, Fatemi, Xianxin.

\section{Cyclic hardening models and material data to $\varepsilon-\mathrm{N}$ analysis}

The quantities necessary to carry out the numerical fatigue analysis can be divided into three groups. The first of these are constants obtained from the tensile test or from the literature material data from which the blade is constructed. The second group is fatigue constants estimated on the basis of data from a static tensile test (necessary for $\varepsilon-\mathrm{N}$ analysis, based on the Manson-CoffinBasquin equation [17] (MCB) presented on Fig. 1. The third group is material data related to material and curve hardening Ramberg-Osgood. Mit(e) represents amplitude of elastic strain $-\varepsilon_{\mathrm{e}}\left(\mathrm{N}_{\mathrm{f}}\right)$ and $\operatorname{Mit}(\mathrm{p})$ represents amplitude of plastic strains $-\varepsilon_{\mathrm{p}}\left(\mathrm{N}_{\mathrm{f}}\right)$, calculated based on equations 3 .

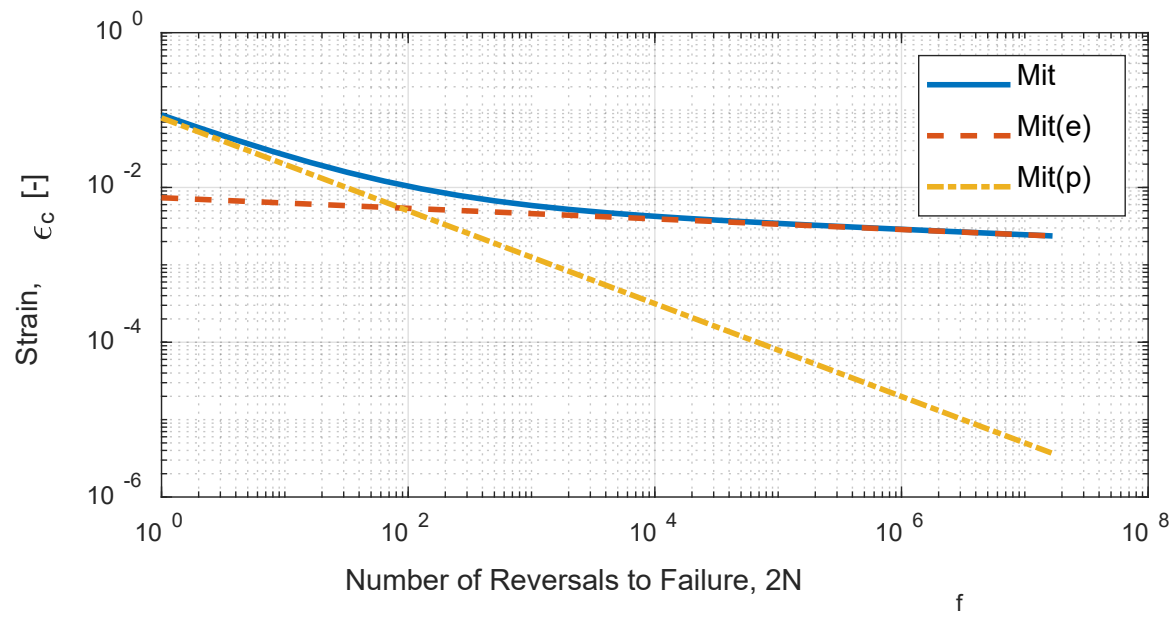

Fig. 1. Manson-Coffin-Basquin fatigue model of EI-961 steel, created based on the Mitchell (Mit) method of estimation fatigue data

The MCB method is based on the assumption that fatigue occurs at constant deformation (both elastic and plastic). The total strain amplitude $\frac{\Delta \varepsilon}{2}$ is held by combining the elastic and plastic component of the function (1). $\frac{\Delta \varepsilon}{2}$ is calculated from the formula of Manson-Coffin-Basquin (MCB):

where:

$$
\frac{\Delta \varepsilon}{2}=\frac{\varepsilon_{\mathrm{e}}+\varepsilon_{\mathrm{p}}}{2}=\frac{\sigma_{\mathrm{f}^{\prime}}}{\mathrm{E}}\left(2 \mathrm{~N}_{\mathrm{f}}\right)^{\mathrm{b}}+\varepsilon_{\mathrm{f}}^{\prime}\left(2 \mathrm{~N}_{\mathrm{f}}\right)^{\mathrm{c}}
$$

$\frac{\Delta \varepsilon}{2}-$ total strain amplitude,

$\varepsilon_{e}-$ elastic strain,

$\varepsilon_{p}$ - plastic strain,

$\Delta \sigma-2 \mathrm{x}$ the stress amplitude, $\mathrm{MPa}$,

$\mathrm{E}-$ modulus of elasticity, Young modulus, GPa,

$2 \mathrm{~N}_{\mathrm{f}}-$ number of reversals to failure,

$\sigma_{\mathrm{f}}{ }^{\prime}-$ fatigue strength coefficient, 
b - fatigue strength exponent (Basquin's exponent),

$\varepsilon_{\mathrm{f}}{ }^{\prime}-$ fatigue ductility coefficient,

c - fatigue ductility exponent.

The fatigue strength exponent $b$ is associated with elastic deformations in the MCB model. This value affects the slope of the line defining the value of elastic deformations of the MCB model. Simultaneously, the fatigue ductility exponent $\mathrm{c}$ is associated with the slope of a plastic strain line.

Due to the fact that steels are characterized by the phenomenon of hardening due to load $[2,5$, $7,8,11,13]$, fatigue analysis is based on the material model proposed by Ramberg-Osgood (RO) [11], developed for the cyclical hardening curve (2):

$$
\Delta \varepsilon=\frac{\Delta \sigma}{\mathrm{E}}+2\left(\frac{\Delta \sigma}{2 \mathrm{~K} \prime}\right)^{1 / \mathrm{n}^{\prime}},
$$

$\Delta \sigma-2 \mathrm{x}$ the stress amplitude, $\mathrm{MPa}$,

$\mathrm{K}^{\prime}$ - cyclic strength coefficient, MPa,

$\mathrm{n}^{\prime}$ - cyclic strain hardening exponent.

In this work, the first stage compressor blade of the aircraft engine, made of EI-961 alloy [14, 15], were investigated. Fatigue material data of EI-961 steel $(0.1-0.16 \% \mathrm{C}$, $\max 0.6 \% \mathrm{Si}$, max $0.6 \%$ Mn, $1.5-1.8 \% \mathrm{Ni}$, max $0.03 \% \mathrm{~S}$, max $0.03 \% \mathrm{P}, 10.5-12 \% \mathrm{Cr}, 0.35-0.5 \mathrm{Mo}, 1.6-2 \% \mathrm{~W}, 0.18-0.3 \%$ $\mathrm{V})$ has been estimated based on the following mechanical properties:

- modulus of elasticity $\mathrm{E}=200 \mathrm{GPa}$,

- Poisson ratio $\gamma=0.3$,

- ultimate tensile strength $U T S=1200 \mathrm{MPa}$,

- failure stain $\varepsilon_{\mathrm{f}}=0.12$.

This data was also used during numerical analysis.

Before the numerical fatigue analysis $(\varepsilon-\mathrm{N})$, it was necessary to determine the fatigue constants of the EI-961 steel for the construction of the Manson-Coffin-Basquin (MCB) model. As a fatigue model of the material, in this work, the Mitchell model was chosen (created in 1977) [9]. This model is characterized by the simplicity of determining fatigue quantities and the fact that the calculations are based only on $\mathrm{R}_{\mathrm{m}}$ and $\varepsilon_{\mathrm{f}}$ (two quantities read from a static tensile test). The models describing the Mitchell model are as follows (3):

$$
\begin{gathered}
\sigma_{\mathrm{f}}^{\prime}=U T S+345 \mathrm{MPa}=1545 \mathrm{MPa}, \\
\varepsilon_{\mathrm{f}}^{\prime}=\varepsilon_{\mathrm{f}}=0.12, \\
\mathrm{~b}=\frac{1}{6} \cdot \ln \frac{0.5 \cdot \mathrm{UTS}}{\sigma_{\mathrm{f}}^{\prime}}=-0.068, \\
\mathrm{c}=-0.6,
\end{gathered}
$$

Regarding the material data necessary to determine the Ramberg-Osgood curve [11, 13]; there are three methods for their approximation. The first method was developed by Manson [7, 8] and published in 1964. Constants are determined based on the following formulas (4):

$$
\begin{gathered}
\mathrm{n}^{\prime}=0.2, \\
\mathrm{~K}^{\prime}=\frac{\sigma_{\mathrm{f}}^{\prime}}{\varepsilon_{\mathrm{f}}^{\prime^{0.2}}}=2360.98 \mathrm{MPa},
\end{gathered}
$$

Another method, created by Fatemi (2000) [2, 12], determines the coefficient and exponent of the cyclic hardening based on the following formulas (5):

$$
\begin{gathered}
\mathrm{n}^{\prime}=\frac{\mathrm{b}}{\mathrm{c}}=0.1141, \\
\mathrm{~K}^{\prime}=\frac{\sigma_{\mathrm{f}}^{\prime}}{\varepsilon_{\mathrm{f}}^{\prime \mathrm{n}^{\prime}}}=1967.88 \mathrm{MPa},
\end{gathered}
$$


The third method, developed by Xianxin, Peizheng, and Xuejun in 1993 [18], suggests the use of the following formulas (6):

$$
\begin{aligned}
& \mathrm{N}^{\prime}=\frac{\log \left[1.73 \cdot\left(\frac{\sigma_{\mathrm{f}}}{\mathrm{UTS}}\right)^{0.536}\right]}{\log \left[36.2 \cdot \varepsilon_{\mathrm{f}}^{0.75}\right]-\log \left[1-81.8 \cdot \frac{\mathrm{UTS}}{\mathrm{E}} \cdot\left(\frac{\sigma_{\mathrm{f}}}{U T S}\right)^{0.179}\right]}=0.1665, \\
& \mathrm{~K}^{\prime}=\frac{0.933 \cdot \mathrm{UTS} \cdot\left(\frac{\sigma_{\mathrm{f}}}{\mathrm{UTS}}\right)^{0.74}}{0.125^{\mathrm{n}^{\prime}} \cdot \varepsilon_{\mathrm{f}}{ }^{0.75 \mathrm{n}^{\prime}}}=1775.535 \mathrm{MPa},
\end{aligned}
$$

\section{Numerical fatigue analysis}

Numerical fatigue analysis was conducted in Ansys Software. In the first step, the geometrical model of the blade with the preliminary defect was built. The analysed blade was originally used in the first stage of the compressor of the aircraft engine PZL-10W. This engine was used to drive a helicopter W-3 Sokol (produced by PZL-Swidnik, Poland).

The created geometrical model contained damage - preliminary notch. A V-notch was located $3 \mathrm{~mm}$ above the foot of the blade, on the leading edge. The depth of the notch was equal to $0.5 \mathrm{~mm}$. Geometrical model of the blade was presented on Fig. 2a. This model was inserted into Ansys Workbench program. Additionally, the material and fatigue constants of the EI-961 were introduced. As a boundary condition, all degrees of freedom have been blocked on the side surfaces of the blade root (Fig. 2a). The geometrical notch is characterized by the lack of pre-stresses and it could be identified with the notch created by subtractive manufacturing.

Based on a geometrical model (Fig. 2a); a discrete model to finite element analysis was prepared. A mash was created by TET-10 elements (with a square shape functions). Additionally, a higher density of elements (smaller size) was defined in the vicinity of the notch (Fig. 2c). Thanks to this approach, the number of elements needed to perform calculations has been minimized, while ensuring satisfactory results of the numerical analysis.

The obtained discrete model of the blade and material model was used in the harmonic mechanical analysis. Based on the harmonic analysis, the stress and strain distribution, during resonance was obtained. The first mode of resonance appears in frequency equal to $786 \mathrm{~Hz}$. This analysis was conducted for the linear-elastic model (based only on Young modulus and Poisson ratio). The amplitude of the displacement during the resonance was equal to $\mathrm{EL}=1.8 \mathrm{~mm}$ (the same as in mentioned earlier papers $[14,15])$.

As a result of the conducted analyses, the values of stresses in the blade were estimated. In this study, the equivalent $\sigma_{\mathrm{HMH}}$, maximum principal $\sigma_{1}$ and directional stresses $\sigma_{\mathrm{Z}}$ (related to the height of the blade) were investigated.

It was determined that the maximum value of equivalent stresses $\left(\sigma_{\mathrm{HMH}}=987 \mathrm{MPa}\right)$ is located in the bottom of the notch, at a distance of $0.2 \mathrm{~mm}$ from the inner side of the blade (Fig. 3a). Information about the location of the highest value of the equivalent stress also give information were should be observed a crack origin and from where the crack should start to propagate. For comparison, the maximum principal stresses amounted to $\sigma_{1}=1171 \mathrm{MPa}$ (Fig. 3b). The largest value of $Z$ directional stress was $\sigma_{\mathrm{Z}}=1163 \mathrm{MPa}$ (Fig. 3c). This value is smaller by only $8 \mathrm{MPa}$ from maximal $\sigma_{1}$. This means that the stresses associated with stretching of the element are mainly a source of deformation.

Obtained results of stress (from the linear elastic model) were used to counting elastic and plastic strain during bending of the blade (the first mode of resonance vibration has bending shape). This approximation is realized by the Ramberg-Osgood equation. Total strains from the above calculations are the basis of a number of load cycles until failure (obtained based on Manson-CoffinBasquin equation). Fatigue load cycles in resonance vibration are symmetric, cyclic with mean stress $\sigma_{\mathrm{m}}$ equal to 0 (load asymmetry factor $\left.\mathrm{R}=\sigma_{\min } / \sigma_{\max }=-1\right)$. 


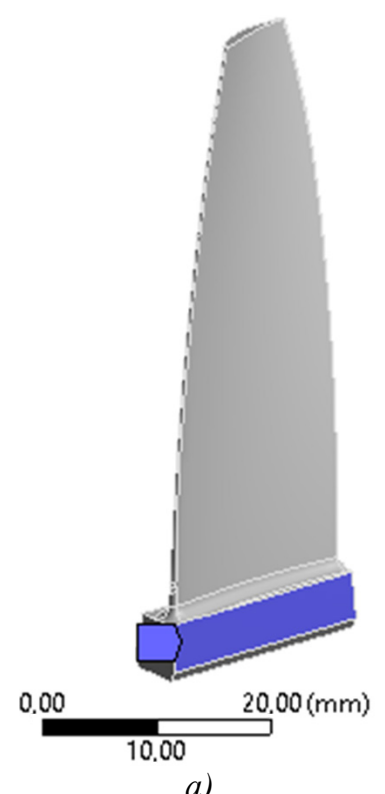

a)

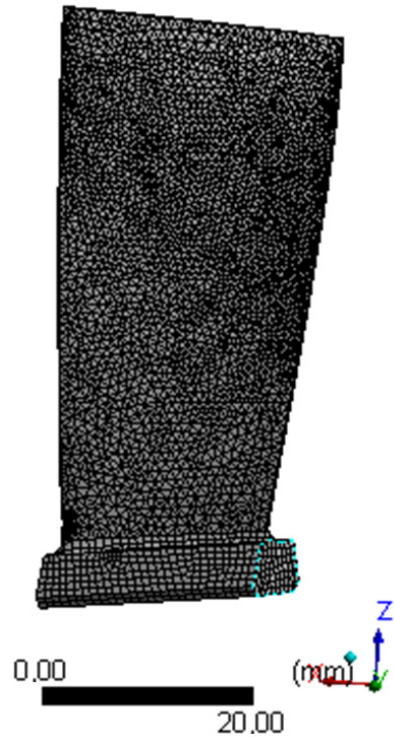

b)

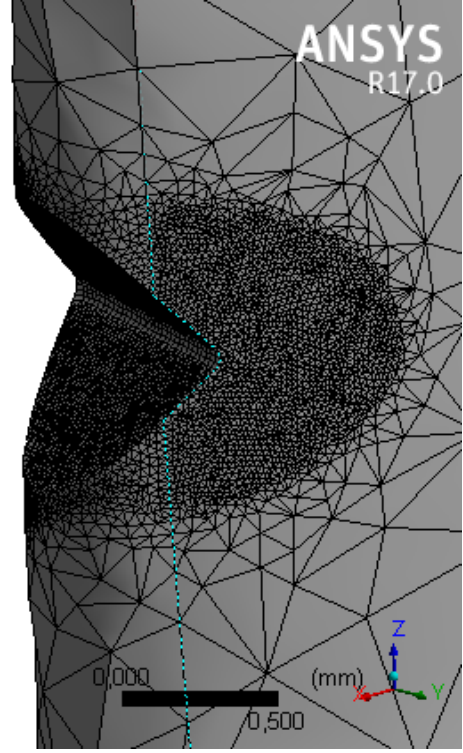

c)

Fig. 2. View of the geometrical model with fixed surfaces (a) and discrete model of the whole blade (b) and magnified view of the notch (c)

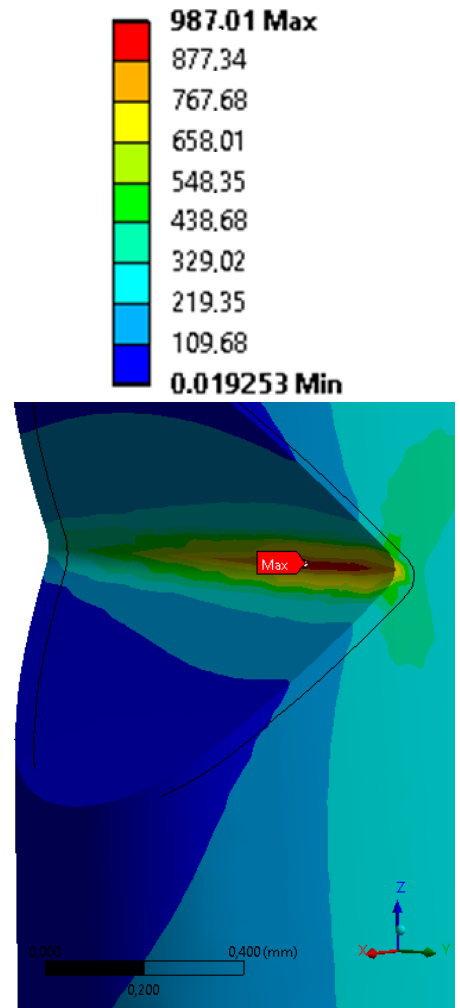

a)
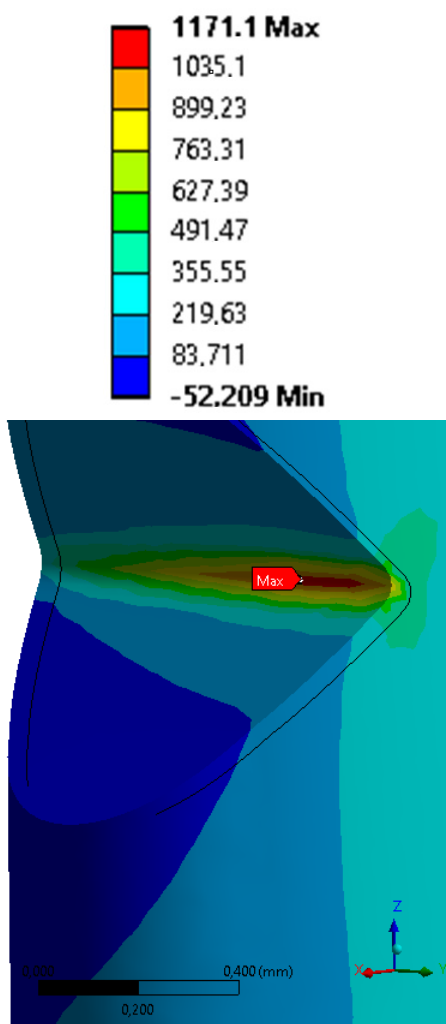

b)
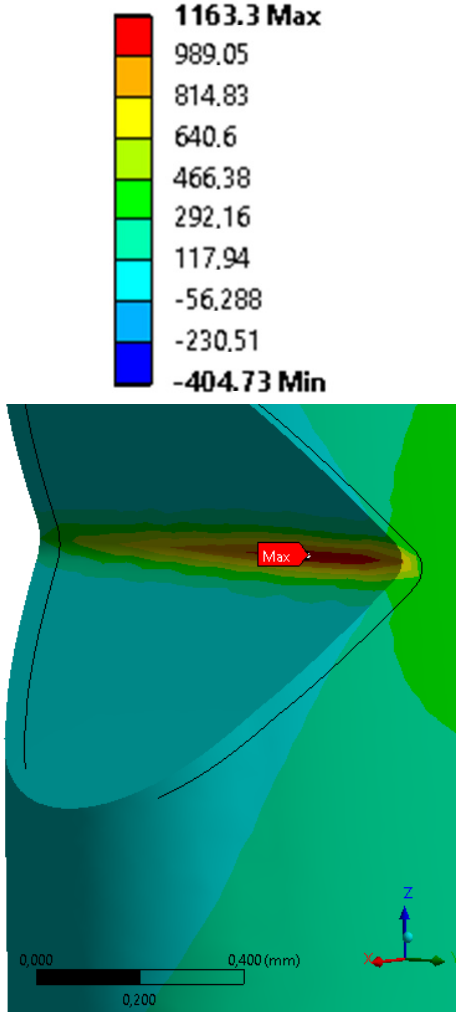

c)

Fig. 3. Distribution of the stress (MPa) in the vicinity of the notch: $\sigma_{H M H}(a), \sigma_{1}(b) \sigma_{Z}(c)$, for the blade working in resonance (I mode, amplitude $A=1.8 \mathrm{~mm}$ )

As mentioned previously, three types of stress and three types of hardening models were used to calculate the number of reversals to failure. Results of this analysis were placed in Tab. 1. In every case of hardening model, the highest durability was observed in case of analysis where the basic was equivalent stress $\sigma_{\mathrm{HMH}}$. This result is due to the fact that the equivalent stresses were of the smallest value (among all analyzed stresses). In the case of $\sigma_{\mathrm{HMH}}$, the highest strength was observed for Fatemi model of hardening $\mathrm{N}_{\mathrm{f}}=1516$ number of load cycles to failure. On the other hand, the 
smallest durability was observed in case of Xianxin model $\left(\mathrm{N}_{\mathrm{f}}=414\right)$. Regarding the basic stress used in numerical fatigue analysis, the lowest durability was obtained for analysis based on maximum principal stress. As with $\sigma_{\mathrm{HMH}}$, the highest durability was obtained for the Fatemi hardening model $\left(\mathrm{N}_{\mathrm{f}}=414\right)$, while the smallest for the Xianxin model $\left(\mathrm{N}_{\mathrm{f}}=149\right)$. The durability results, in relation to stresses $\sigma_{\mathrm{Z}}$, are similar to those based on stresses $\sigma_{1}$.

Tab. 1. Results of numerical fatigue analysis

\begin{tabular}{c|ccc}
\multirow{2}{*}{ Type of stress } & \multicolumn{3}{|c}{ Type of hardening model to Ramberg-Osgood equation } \\
\cline { 2 - 4 } & Manson & Fatemi & Xianxin \\
\hline$\sigma_{\text {HMH }}$ & 539 & 1516 & 414 \\
$\sigma_{1}$ & 191 & 414 & 149 \\
$\sigma_{\mathrm{Z}}$ & 199 & 435 & 155
\end{tabular}

As shown by the obtained results, the following factors have a significant influence on the results of numerical fatigue analysis: stress type used to estimate plastic strain (based on the RO model) as well as the method of estimating constants to the metal hardening model. The use of the Fatemi model can cause a threefold increase in fatigue life (in relation to results based on the Xianxin or Manson model). The Manson model is the simplest. It assumes a constant value of cyclic strain hardening exponent and makes the cyclic strength coefficient dependent on the values associated with the MCB model. Conversely, the Xianxin methodology for determining constant hardening is the most complex and takes into account many material data (as well as contains a number of values permanently locked in the equations). The Fatemi method is similar to the Manson method, with the difference that the Fatemi method takes into account the fatigue constants from MCB equation also in determining the cyclic strain-hardening exponent. Due to the above, in the case of the Mitchell model (for fatigue based on MCB), the cyclic strain-hardening exponent is nearly two times lower in the case of the Fatemi's hardening model than in the Manson model. Interestingly, the highest value of the cyclic strength coefficient was obtained for the Manson model $\left(\mathrm{K}^{\prime}=2361 \mathrm{MPa}\right)$, and the smallest for the Xianxin model $\left(\mathrm{K}^{\prime}=1776 \mathrm{MPa}\right)$.

In the last step of this work, the obtained results of numerical fatigue analysis will be compared with the experimental results. The methodology of experiment and information about the condition during tests were presented in Witek's papers $[14,15]$. The crack origin was located in the top of the notch, moved away from the inner side of the compressor blade. The location of the crack origin (in experimental tests) is similar to the location of the maximal values of stresses from numerical analysis.

Additional exams show that microcrack (with length $\mathrm{a}=0.2 \mathrm{~mm}$ ) were conducted after $12.9 \times 10^{3}$ load cycles. This number of load cycles until failure is from 9 to 86 time higher than the biggest and smallest numerical results.

\section{Conclusion}

The influence of the cyclic hardening model on the results of the numerical fatigue analysis was obtained in this paper. The highest value of a number of load cycles until failure was observed in case of Fatemi hardening model. The smallest durability was observed for Xianxin model. Additionally, this paper also shown the impact of the stress used in the numerical $\varepsilon-\mathrm{N}$ analysis was executed. In case of compressor blade under resonance vibrations, the maximum principal stress $\sigma_{1}$ was similar to $\sigma_{\mathrm{Z}}$. Values of equivalent stress $\sigma_{\mathrm{HMH}}$ were smaller than the other mentioned.

Numerical results of the stresses showed that the crack origin should be located in the bottom of the V-notch, distant from the inner side of the blade. Similar observation was made in experimental studies. 
Obtained results of fatigue life, reached in numerical analyses are much smaller than the results of experimental tests. It could be influenced by additional surface treatment, inaccuracy of the numerical model of the material and also the phenomenon of resonance itself. By default, the material sizes for the analysis based on the MCB model refer to the sample performed at $10 \mathrm{~Hz}$. The frequency during the experiment was nearly 79 times greater, which could also increase the number of cycles to initiate fatigue cracking.

\section{Acknowledgment}

The research leading to these results was co-financed from funds for the statutory activity of Department of Aircrafts and Aircraft Engines, Rzeszow University of Technology (DS.ML.19.001) and also the Fulbright Program (sponsored by U.S. Department of State).

\section{References}

[1] Carter, T. J., Common failures in gas turbine blade, Eng. Failure, 12, pp. 237-247, 2005.

[2] Chengzong, L., Zhiyong, Z., Xin, C., Yuanxiao, S., Low-Cycle Fatigue Analysis and Experiment of Steel Specimens with Stress Concentration, Journal of Applied Mechanics, 17 Vol. 3, pp. 107-110, 2000.

[3] Ejaz, N., Salam, I., Taugir, A., An air crash due to failure of compressor rotor, Engineering Failure Analysis, 14, pp. 831-840, 2007.

[4] Hamrick, J. L., Effects of foreign object damage from small hard particles on the high-cycle fatigue live of T1-6A1-4V, PhD Dissertation, Air Force Institute of Technology, 1999.

[5] Ince, A., Glinka, G., A modification of Morrow and Smith-Watson-Topper mean stress correction models, Fatigue \& Fracture of Engineering Materials \& Structures, 34, pp. 854867, 2011.

[6] Mall, S., Hamrick, J. L., Nicholas, T., High cycle fatigue behavior of Ti-6Al-4V with simulated foreign object damage, Mechanics of Materials, 33, pp. 679-692, 2001.

[7] Manson, S. S., Hirschberg, M. H., Fatigue behavior in strain cycling in the low and intermediate cycle range, Fatigue - An interdisciplinary Approach, Proceedings of the 10th Sagamore Army Materials Research Conference, pp. 133-173, 1964.

[8] Manson, S. S., Fatigue: A Complex Subject - Some Simple Approximation, Experimental Mechanical Journal, 5, pp. 193-226, 1965.

[9] Meggiolaro, M. A., Castro, J. T. P., Statistical evaluation of strain-life fatigue crack initiation predictions, International Journal of Fatigue, 26, pp. 463-476, 2004.

[10] Nakhodchi, S., Salimpour, M. E., Fatigue life prediction in damaged and un-damaged compressor blades, Engineering Solid Mechanics, 2, pp. 43-50, 2013.

[11] Niesłony, A., Kurek, A., Badania kompatybilności pomiędzy modelami Mansona-CoffinaBasquina $i$ Ramberga-Osgooda na podstawie wybranych materiałów konstrukcyjnych, Czasopismo Techniczne: Mechanika, 108, pp. 53-64, 2011.

[12] Stephens, R.I., Fatemi, A., Stephens, R. R., Fuchs, H. O., Metal Fatigue in Engineering, John Wiley\& Sons, Ottawa, Canada 2000.

[13] Visvanatha, S. K., A study of the use of Neuber's Rule in fatigue crack initiation predictions, Carleton University, Ottawa, Canada 1998.

[14] Witek, L., Bednarz, A., Stachowicz, F., Fatigue analysis of compressor blade with preliminary defect, Engineering Failure Analysis, 58, 139, pp. 229-237, 2015.

[15] Witek, L., Bednarz, A., Impact of the vibration amplitude on the fatigue life of compressor blades with mechanical defects, Journal of KONES, Vol. 23, pp. 571-576, 2016.

[16] Xi, N. S., Zhong, P. D., Huang, H. Q., Yan, H., Tao, C. H., Failure investigation of blade and disk in first stage compressor, Engineering Failure Analysis, 7, pp. 385-392, 2000. 
[17] Xianxin, C., Peizheng, R., Xuejun, L., Feng, T., Approximate Estimation for Strain Fatigue Parameters, Proceedings of the 6th National Conference on Fatigue, The Chinese Society of Theoretical and Applied Mechanics, pp. 232-235, 1993.

[18] Zhang, Z., Qiao, Y., Sun Q., Li, C., Li, J., Theoretical estimation to the cyclic strength coefficient and the cyclic strain-hardening exponent for metallic materials, Preliminary study, Journal of Materials Engineering and Performance, 18, pp. 245-254, 2009.

Manuscript received 06 March 2019; approved for printing 21 June 2019 